Foreword

\title{
Precision Surgery in Obstetrics and Gynecology: Cesarean Section
}

\author{
Yuji Hiramatsu, MD, $\mathrm{PhD}^{1}$ \\ ${ }^{1}$ Department of Obstetrics and Gynecology, Okayama City General
Medical Center, Kita-Ku, Okayama, Japan \\ Surg J 2020;6(suppl S2):S71.
}

It is a great pleasure to publish the third issue of Precision Surgery in Obstetrics and Gynecology (PSOG), a supplement to The Surgery Journal. The third issue of PSOG focuses on "Cesarean Section."

We previously published a Japanese book series (24 volumes), entitled Obstetric and Gynecologic Surgery Now (OGS Now), ${ }^{1}$ with the Japanese medical publisher, Medical View Inc. In PSOG, we are selecting representative operations from OGS Now series and demonstrating the updated operative techniques.

Cesarean section is the most frequent and essential obstetrical surgery. When performing a cesarean section, the difficulty of the operation varies greatly depending on gestational weeks, fetal lie, location of the placenta, degree of placental adhesion, and the presence of uterine myoma. In this special issue, we asked experts to explain the basic procedures for cesarean section and how to deal with them in various situations. All of the papers published in this volume were written by the experts in this field in Japan and are explained using easy-to-understand illustrations and photographs that show the sur-

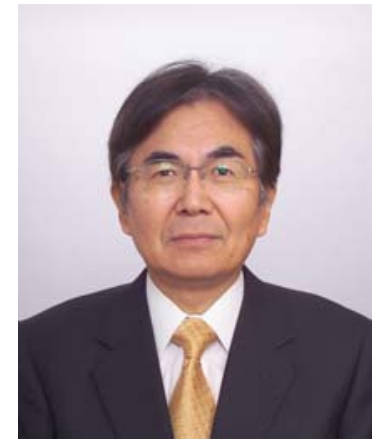

Yuji Hiramatsu, MD, PhD gical techniques, tips, and precautions. We hope that the procedures listed in PSOG will be helpful in performing basic and difficult cesarean section.

Finally, I would like to express my sincere thanks to Medical View Inc. for allowing us to use the illustrations and photos used in the OGS Now series.

\section{Conflict of Interest}

None.

\section{Reference}

1 Hiramatsu Y, Konishi I, Sakuragi N, Takeda S. Obstetric and Gynecologic Surgery Now (OGS Now). Vol. 1-24. Tokyo: Medical View; 2010-2015
Address for correspondence Yuji Hiramatsu, MD, PhD, Okayama City General Medical Center, 3-20-1 Kitanagase Omotematchi, Kita-Ku, Okayama, 700-8557, Japan (e-mail: hiramatsu.enyu@gmail. com).
DOI https://doi.org/

10.1055/s-0040-1714722. ISSN 2378-5128.
Copyright $\odot 2020$ by Thieme Medical Publishers, Inc., 333 Seventh Avenue, New York, NY 10001, USA. Tel: +1(212) 760-0888.

\section{License terms \\ (ㄷ) (1) $\ominus \circledast$}

